\title{
Early stage prostate cancer: biochemical recurrence after treatment
}

Danielle A. Zanatta, Reginaldo J. Andrade, Eduardo F. Pacagnan, Lucas W. München, Rosangela A. B. Assumpção, Vanesssa C. F. I. Mercante, Gustavo M. D. Simonetti

Assis Gurgacz (FAG) Medical School (DAZ, LM); Clinical oncologist of the Cancer Hospital of Cascavel, UOPECCAN (RJA); Brazilian Society of Urology (EFP), Rio de Janeiro, RJ; Federal Technological University of Paraná, UTFPR (RABA), Toledo; Department of Radiotherapy (VCFM) and Department of Medical Physics (GMDS), Cancer Hospital Cascavel - UOPECCAN, Cascavel, PR, Brazil

\section{ABSTRACT}

Objectives: To identify retrospectively through chart analysis the biochemical recurrence frequency of localized prostate cancer at diagnosis of patients submitted to surgery or radiotherapy; to correlate diagnostic characteristics associated with higher risk of biochemical recurrence.

Materials and Methods: Retrospective analysis of 483 patients treated in a single center, from March 2000 to December 2009 in order to verify factors associated with biochemical recurrence.

Results: Biochemical recurrence was more frequent in patients with higher initial PSA levels and those with higher risk disease. Recurrence was more frequent in patients with high risk (25.9\%) than those with intermediate risk (10.7\%) and low risk (5.5\%). There was no significant statistical difference of biochemical recurrence between patients submitted to radiotherapy or radical prostatectomy. Biochemical recurrence was diagnosed in only 11 of 73 patients (15\%) submitted to conformal radiotherapy using tridimensional technique.

Conclusion: Radiotherapy and radical prostatectomy have similar treatment results. Tridimensional conformal radiotherapy used nowadays is more efficient than earlier forms of radiation therapy (cobalt therapy and bidimensional linear accelerator therapy).

\section{ARTICLE INFO}

Key words:

Prostate; Prostatic Neoplasms;

Prostatectomy; Radiotherapy

Int Braz J Urol. 2014; 40: 137-45

Submitted for publication:

July 27,2013

Accepted after revision:

October 2, 2013

\section{INTRODUCTION}

Prostate cancer is the second more prevalent malignant tumor in men (skin cancer other than melanoma being the first); in 2008 it was estimated 900.000 cases and 258.000 deaths due to the disease (1).

In 2012 it was estimated nearly 60.000 new patients with prostate cancer in Brazil: 62 new cases for every 100.000 men (2). It is the most prevalent malignant tumor in the Southeast region (78/100.000); in Midwest 75/100.000, in South 68/100.000, Northeast 43/100.000 and in North region 30/100.000 (2).

Treatment options for localized disease include radical prostatectomy and radiotherapy, with similar results (3).

Biochemical recurrence is characterized by PSA elevation following primary treatment. It usually precedes often for many years, clinical recurrence and progression of the disease. 


\section{MATERIAL AND METHODS}

From March 2000 to December 2009, 819 patients with prostate cancer were treated at Cancer Hospital of Cascavel - UOPECCAN. From these, 483 had non-metastatic disease at diagnosis and were treated with curative purposes (radiotherapy or radical prostatectomy) and were followed in an out-patient basis at the institution.

The present study is a retrospective analysis of the evolution of these 483 patients, in order to identify biochemical recurrence and related factors.

Radical prostatectomy (RP) was performed by a trained group of urologists and radiotherapy (RT) evolved along the years, being divided in three phases: first phase, from March 2000 to September, 2004, it was used cobalt radiotherapy (RTCo). From October 2004 to August 2008, patients were submitted to bidimensional linear accelerator radiotherapy (RT2D) and from September 2008 on it was used conformal tridimensional RT linear accelerator (RT3D).

Patients were divided in three risk groups concerning biochemical recurrence: low risk (PSA $<10 \mathrm{ng} / \mathrm{mL}$ and Gleason $\leq 6$ ), intermediate (PSA between 10 and $20 \mathrm{ng} / \mathrm{mL}$ or Gleason $=7$ ) and high risk (PSA > 20ng/mL or Gleason 8 to 10). The first group (low risk) encompasses patients with very low risk and low risk cited in previous studies (4).

Biochemical recurrence was considered when it was observed a rise of PSA following PR in two different occasions ( $>0.2 \mathrm{ng} / \mathrm{mL}$ ).

Biochemical recurrence in patients submitted to RT was considered when the PSA level exceeded $2 \mathrm{ng} / \mathrm{mL}$ from the lowest post-treatment value (nadir).

Diagnostic characteristics (PSA, Gleason score, risk categories) and treatment modalities (RP or RT) were submitted to statistical analysis in order to identify the risk of biochemical recurrence using the chi-square or Fisher tests (when the sample was small) and the t-Student test. Significance level was 5\% $(p=0.05)$.

\section{RESULTS}

Four hundred eighty-three patients were treated with localized disease at diagnosis. Age varied from 41 to 90 years (median $=68$ years) Time between diagnosis and treatment varied from two to 621 days (median $=54$ days). Table- 1 shows the distribution according to Gleason score, serum PSA and risk stratification.

Table 1 - Patients characteristic before treatment.

\begin{tabular}{lc}
\hline Characteristics & Total patients (\%) \\
\hline Gleason $<7$ & $353(73)$ \\
Gleason $=7$ & $100(21)$ \\
Gleason 8-10 & $030(6)$ \\
PSA $<10$ & $200(41.4)$ \\
PSA 10 - 20 & $155(32.1)$ \\
PSA $>20$ & $128(26.5)$ \\
Low risk & $155(32.1)$ \\
Intermediate risk & $184(38.1)$ \\
High risk & $144(29.8)$ \\
\hline
\end{tabular}

PSA $=$ Prostatic Specific Antigen

Table-2 shows the classification of patients according to risk factors and treatment modality.

PSA was higher in patients submitted to RT than those submitted to RP ( $p<0.05$ ). There was also a higher number of high risk patients among those submitted to RT ( $p<0.05)$. Table-3 shows the risk factors and biochemical recurrence prior treatment.

Biochemical recurrence was identified in 180 patients (37.3\%). It was more frequent in patients with higher PSA, higher Gleason and high risk stratification. It was observed in $60 \%$ of patients with Gleason score 8-10, 50\% of those with Gleason 7 and in 31.7\% of patients with Gleason $\leq 6(\mathrm{p}<0.05)$.

Recurrence was more frequent in patients with PSA higher than $20 \mathrm{ng} / \mathrm{mL}$ (61.2\% of patients), when compared to those with PSA $10-20 \mathrm{ng} / \mathrm{mL}$ $(30.3 \%)$ and below 10ng/mL $(27 \%)(p<0.05)$.

More recurrence episodes were also observed in patients with high risk (61.1\%) than those 
Table 2 - Risk factors and modality of treatment.

\begin{tabular}{|c|c|c|c|c|}
\hline Characteristics & $\begin{array}{l}\text { Total of patients } \\
\qquad(n=483)\end{array}$ & $\begin{array}{c}\mathrm{RP} \\
(\mathrm{n}=227)\end{array}$ & $\begin{array}{c}\mathrm{RT} \\
(\mathrm{n}=256)\end{array}$ & $P$ value \\
\hline Gleason $<7$ & 353 & 163 & 190 & 0.55 \\
\hline Gleason $=7$ & 100 & 054 & 046 & 0.06 \\
\hline Gleason 8-10 & 30 & 010 & 020 & 0.12 \\
\hline$P S A<10$ & 200 & 123 & 077 & $<0.05$ \\
\hline PSA $10-20$ & 155 & 076 & 079 & 0.54 \\
\hline$P S A>20$ & 128 & 028 & 100 & $<0.05$ \\
\hline Low Risk & 155 & 097 & 058 & $<0.05$ \\
\hline Intermediate risk & 184 & 094 & 090 & 0.16 \\
\hline High risk & 144 & 036 & 108 & $<0.05$ \\
\hline
\end{tabular}

PSA = Prostatic Specific Antigen; $\mathbf{R P}=$ Radical Prostatectomy; $\mathbf{R T}$ = Radiotherapy

Table 3 - Pre-treatment risk factors and biochemical recurrence.

\begin{tabular}{lccc}
\hline Treatment modality & Total of patients & Total of recurrences(\%) & $p$ value \\
\hline PTR & 227 & $078(34.4)$ & 0.25 \\
RT & 256 & $102(39.8)$ & \\
\multicolumn{1}{l}{ RTC0 } & 033 & $017(51.5)$ & $<0.05$ \\
RT2D & 150 & $074(49.3)$ & \\
RT3D & 073 & $011(15.1)$ & \\
\hline
\end{tabular}

$\mathbf{R P}=$ Radical Prostatectomy; $\mathbf{R T}=$ Radiotherapy; $\mathbf{R T C} \mathbf{0}=$ Cobalt Radiotherapy $\mathbf{R T 2 D}=$ Conformal Bidimensional Radiotherapy; $\mathbf{R T 3 D}=$ Tridimensional Conformal Radiotherapy

with intermediate risk (31\%) and low risk (22\%) $\mathrm{p}<0.05$.

The differences between recurrence levels of different treatment modalities are shown on Table-4 and Figure-1.

There was no statistical difference $(\mathrm{p}=$ $0.25)$ in recurrence between patients submitted to RP (34.4\%) or RT (39.8\%).

Median time of follow-up of patients submitted to RP ( $\mathrm{n}=227$ ) was 1427 days (54 to 3431 days). Time between surgery and biochemical recurrence $(\mathrm{n}=78,34.4 \%)$ varied from 53 to 2451 days (median 502 days, Figure-2). There were more recurrence episodes in patients with Gleason score 8-10, higher initial PSA and those of high risk group.

Recurrence was more frequent in patients with Gleason 8-10 (90\% versus 48\% and 26\%, p $<0.05$ ), PSA > 20ng/mL (68\% versus 30 and 29\%, $\mathrm{p}<0.05)$ and in high risk group (72\% vs. 31 and 28\%, p < 0.05) - Table-5.

The primary treatment of 256 patients was RT; the first 33 patients were treated with cobalt radiotherapy; 147 patients were treated with RT2D and 73 patients received RT3D. 
Table 4 - Biochemical recurrence according to treatment.

\begin{tabular}{lccc}
\hline Characteristic & Total of patients & Biochemical recurrence(\%) & p value \\
\hline Gleason $<7$ & 353 & $112(31.7)$ & $<0.05$ \\
Gleason $=7$ & 100 & $050(50)$ & \\
Gleason 8-10 & 030 & $018(60)$ & $<0.05$ \\
p value & & $054(27)$ & $<0.05$ \\
PSA $<$ 10 & 200 & $047(30.3)$ & \\
PSA 10 - 20 & 155 & $079(61,2)$ & $<0.05$ \\
PSA $>$ 20 & 128 & $034(21.9)$ & $<05$ \\
p-value & & $058(31.5)$ & \\
Low risk & 155 & $088(61.1)$ & $<0.05$ \\
Intermediate risk & 184 & 144 & \\
High risk & & & \\
p-value & & & \\
\hline
\end{tabular}

$\mathbf{R P}=$ Radical Prostatectomy; $\mathbf{R T}=$ Radiotherapy

Figure 1 - Disease-free survival curves (Kaplan-Meier estimates) for RP and RT

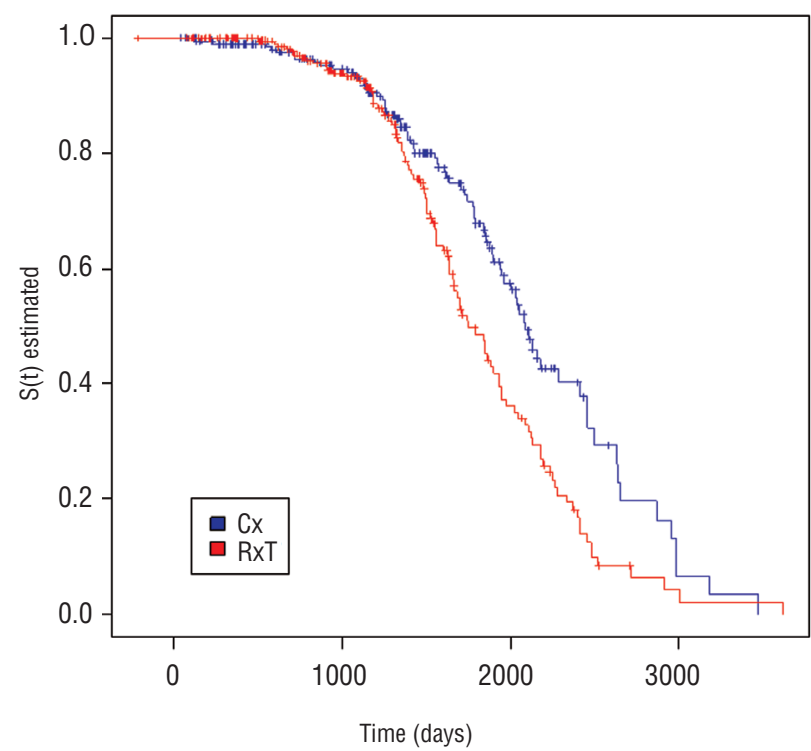

Figure 2 - Disease-free-survival curve (Kaplan-Meier estimates) for RP.

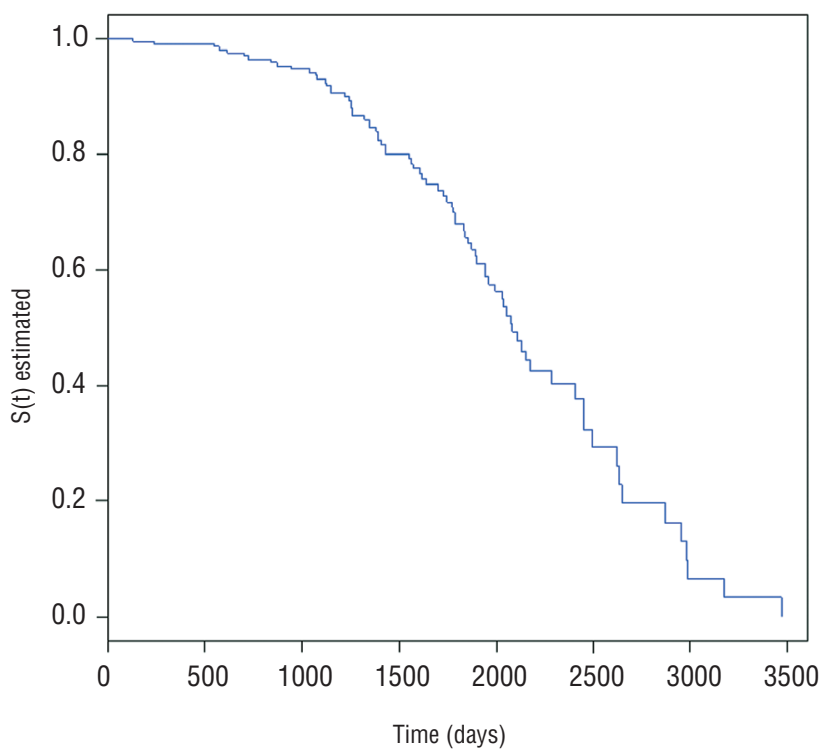

$\mathbf{C x}=$ Prostatectomy; RxT: Radiotherapy.

Mantel-Haenzel test between RP and RT

$\mathbf{X}^{2}=9.5$, freedom grade $=1$ and $p$-value $=0.0021^{*}$ 
Table 5 - Biochemical recurrence after RP.

\begin{tabular}{|c|c|c|c|c|}
\hline \multirow[t]{2}{*}{ Characteristics } & \multirow{2}{*}{ Total } & \multicolumn{2}{|c|}{ Recurrence } & \multirow{2}{*}{$p$ value } \\
\hline & & Yes $(\%)$ & No $(\%)$ & \\
\hline Gleason $<7$ & 163 & $043(26.3)$ & $120(73,6)$ & $<0,05$ \\
\hline Gleason $=7$ & 54 & $026(48.1)$ & $028(51.8)$ & $<0.05$ \\
\hline Gleason 8-10 & 10 & $009(90)$ & $001(10)$ & $<0.05$ \\
\hline $\mathrm{p}$ value & & $<0.05$ & $<0.05$ & \\
\hline$P S A<10$ & 123 & $036(29.2)$ & $087(70.7)$ & 0.1 \\
\hline PSA $10-20$ & 76 & $023(30.2)$ & $053(69.7)$ & 0.4 \\
\hline PSA $>20$ & 28 & $019(67.8)$ & $009(32.1)$ & $<0.05$ \\
\hline $\mathrm{p}$ value & & $<0.05$ & $<0.05$ & \\
\hline Median PSA & & 10.36 & 9.00 & $<0.05$ \\
\hline Low risk & 97 & $023(23.7)$ & $074(76.3)$ & $<0.05$ \\
\hline Intermediate risk & 94 & $029(30.8)$ & $065(69.1)$ & 0.4 \\
\hline High risk & 36 & $026(72.2)$ & $010(27.7)$ & $<0.05$ \\
\hline $\mathrm{p}$ value & & $<0.05$ & $<0.05$ & \\
\hline
\end{tabular}

$\mathbf{P S A}=$ Prostatic Specific Antigen; $\mathbf{R P}=$ Radical Prostatectomy

Follow-up varied from 115 to 3638 days (median 1296 days). Median follow-up of patients treated with cobalt radiotherapy was 1811 days and those submitted to RT2D was 1421 days. As expected, median of follow-up of patients treated with RT3D was lower (1026 days).

There were 102 recurrences after RT (39.8\%, Figure-3). Time between treatment and recurrence varied from 350 to 2532 days (median 685 days). Recurrence was identified in 17 patients treated with RTCo (51.5\%), in 74 with RT2D (50.8\%) and in 11 with RT3D (15.1\%). These differences are significant $(p<0.05)$, Table- 4 and Figure- 4 .

Table- 6 shows the risk factors and biochemical recurrence after radiotherapy. The stratification of patients according to PSA level showed more recurrences in patients with PSA $\geq 20 \mathrm{ng} / \mathrm{mL}$ and intermediate and high risk patients.

More recurrences were identified in patients treated with cobalt radiotherapy (55\%) and
Figure 3 - Disease-free survival curve (Kaplan-Meier estimates) for RT.

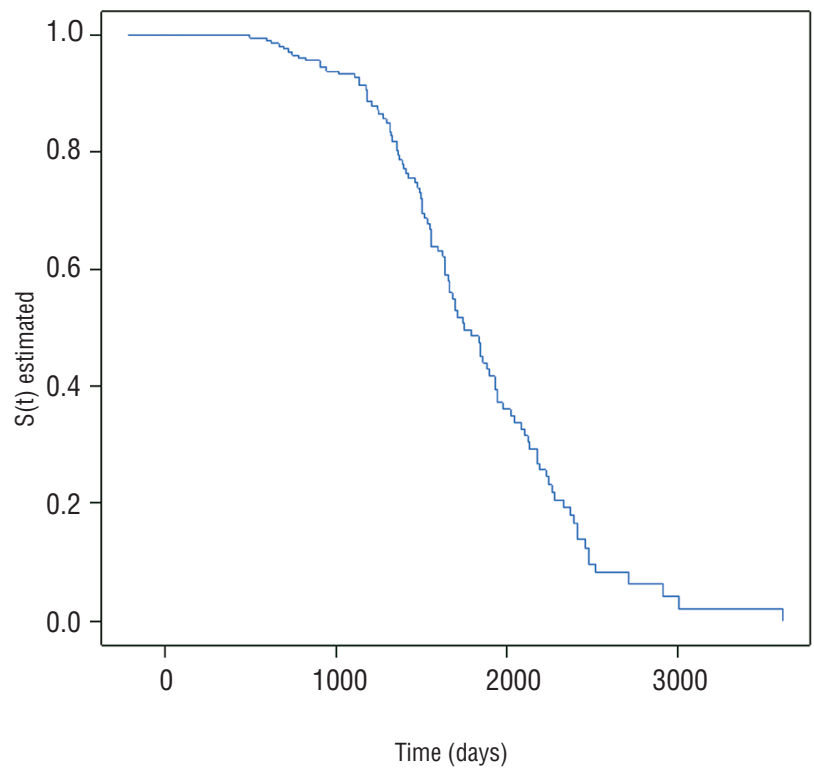


Table 6 - Biochemical recurrence after radiotherapy.

\begin{tabular}{|c|c|c|c|c|}
\hline \multirow[t]{2}{*}{ Characteristics } & \multirow{2}{*}{ Total } & \multicolumn{2}{|c|}{ Recurrence } & \multirow{2}{*}{$p$ value } \\
\hline & & Yes $(\%)$ & No $(\%)$ & \\
\hline Gleason $<7$ & 190 & $069(36.3)$ & $121(63.6)$ & $<0.05$ \\
\hline Gleason $=7$ & 46 & $024(52.1)$ & $022(47.8)$ & 0.67 \\
\hline Gleason 8-10 & 20 & $009(45)$ & $011(55)$ & 0.52 \\
\hline$p$ value & & 0.12 & 0.12 & \\
\hline$P S A<10$ & 77 & $018(23.3)$ & $059(76.6)$ & $<0.05$ \\
\hline PSA 10 - 20 & 79 & $024(30.3)$ & $055(69.6)$ & $<0.05$ \\
\hline$P S A>20$ & 100 & $060(60)$ & $040(40)$ & $<0.05$ \\
\hline$p$ value & & $<0.05$ & $<0.05$ & \\
\hline Median PSA & & 28.97 & 12.20 & $<0.05$ \\
\hline Low risk & 58 & $011(18.9)$ & 047 (81) & $<0.05$ \\
\hline Intermediate risk & 90 & $029(32.2)$ & $061(67.7)$ & $<0.05$ \\
\hline High risk & 108 & $062(57.4)$ & $046(42.6)$ & $<0.05$ \\
\hline$p$ value & & $<0.05$ & $<0.05$ & \\
\hline
\end{tabular}

PSA = Prostatic Specific Antigen

Figure 4 - Disease-free survival curves (Kaplan-Meier estimates) for Rtco, RT2D and RT3D treatments.

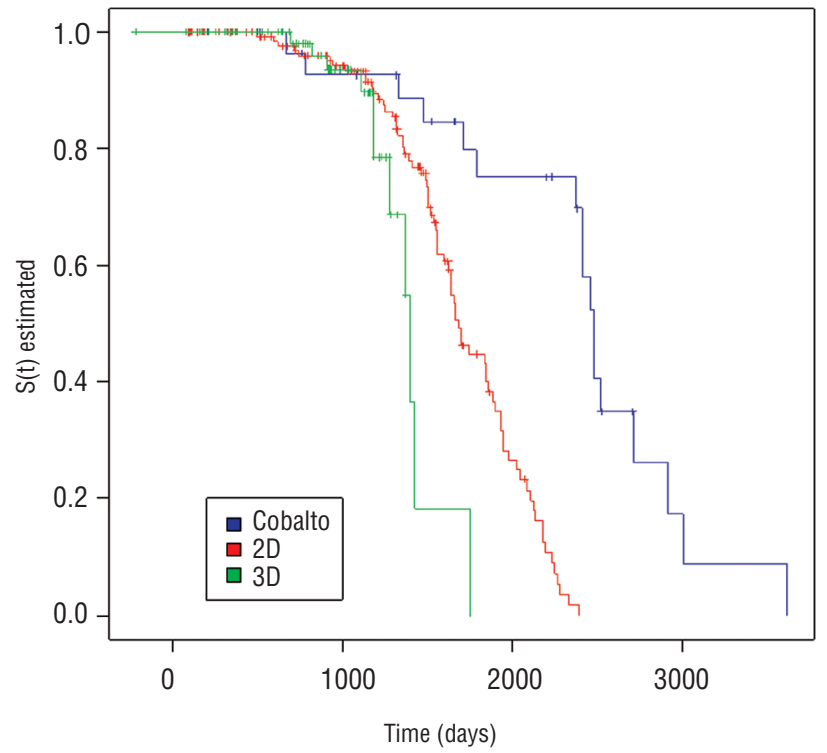

Mantel-Haenzel test among $\mathrm{C} 0,2 \mathrm{D}$ and $3 \mathrm{D}$

$\mathbf{X}^{2}=37.6$, freedom grade $=2$ and $p$-valu $e=0.000^{*}$
RT2D (51\%) than those treated with RT3D (16\%), p $<0.05$, Table-7.

There was no influence of risk factors (Gleason score, PSA and risk stratification) in biochemical recurrence incidence of patients treated with cobalt radiotherapy.

Among patients treated with RT2D, recurrence rate was higher in patients with PSA $\geq 20 \mathrm{ng} / \mathrm{mL}$ (43/56 patients, 77\%) and intermediate risk (22/54 patients, $41 \%$ ) and high risk (45/63 patients, 71\%).

Biochemical recurrence was identified in 11 of 73 patients submitted to RT3D (15\%). Analysis of pre-treatments characteristics did not show any statistical difference among patients classified as high risk (25.9\%), intermediate $(10.7 \%)$ and low risk (5.5\%).

\section{DISCUSSION}

Prostate cancer is frequent and responsible for cancer associated morbidity and mortality. When treated initially, RP of RT are curative (1). 
Table 7 - Biochemical recurrence according to RT modality of treatment.

\begin{tabular}{|c|c|c|c|c|c|}
\hline & $\begin{array}{l}\text { RTCo patients/ } \\
\text { recurrence }\end{array}$ & $\begin{array}{l}\text { RT2D patients/ } \\
\text { recurrence }\end{array}$ & $\begin{array}{l}\text { RT3D patients/ } \\
\text { recurrence }\end{array}$ & \multicolumn{2}{|c|}{$p$ value } \\
\hline Total of patients & $33 / 17$ & $150 / 74$ & $73 / 11$ & \multicolumn{2}{|c|}{$<0.05$} \\
\hline \multicolumn{6}{|l|}{ Characteristics } \\
\hline Gleason $<7$ & 026/015 & $104 / 046$ & 060/008 & $<0.05$ & \\
\hline Gleason $=7$ & 004/001 & 033/020 & 009/003 & 0.18 & 0.26 \\
\hline Gleason 8-10 & 003/001 & 013/008 & $004 / 0$ & 0.08 & \\
\hline$p$ value & 0.4 & 0.17 & 0.25 & & \\
\hline$P S A<10$ & 008/003 & 049/014 & 020/001 & 0.06 & \\
\hline PSA $10-20$ & 008/004 & 045/017 & 026/003 & $<0.05$ & 0.48 \\
\hline$P S A>20$ & 017/010 & 056/043 & 027/007 & $<0.05$ & \\
\hline$p$ value & 0,61 & $<0.05$ & 0.11 & & \\
\hline Median PSA & 23.0 & 21.2 & 28.5 & -- & \\
\hline Low risk & $007 / 003$ & 033/007 & 018/001 & 0.09 & \\
\hline Intermediate risk & 008/004 & 054/022 & 028/003 & $<0.05$ & 0.53 \\
\hline High risk & 018/010 & 063/045 & 027/007 & $<0,05$ & \\
\hline$p$ value & 0.84 & $<0.05$ & 0.14 & & \\
\hline
\end{tabular}

PSA = Prostatic Specific Antigen; $\mathbf{R T C} \mathbf{0}=$ Cobalt radiotherapy; $\mathbf{R T 2 D}=$ Bidimensional conformal radiotherapy; $\mathbf{R} \mathbf{T} \mathbf{3}$ = Tridimensional conformal radiotherapy

Sustained elevation of PSA in any moment after treatment is related to the existence of viable prostatic tissue anywhere. Biochemical recurrence precedes the beginning of clinical disease in the majority of cases (5-7).

The concept of biochemical recurrence is not consensual in literature and varies according to the primary treatment (RP or RT) (8-10).

A widely accepted definition of biochemical recurrence after surgery is of a serum PSA greater than $0.2 \mathrm{ng} / \mathrm{mL}$ in two different consecutive samples after treatment (11-13). Biochemical recurrence following radiotherapy is defined at present when serum PSA is equal or greater than 2ng/ $\mathrm{mL}$ above the original lower level of PSA (nadir) following radiotherapy (14).
The present study analyzed a great number of patients with localized prostate cancer submitted to RP or RT in a single institution.

The criteria of biochemical recurrence after RP was PSA > 0.2. Although many authors consider PSA $>0.4$, PSA $>0.2$ is widely used in literature and probably more suitable due to more precise and sensitive detection methods (8-12).

Results showed that prognostic factors at diagnosis, PSA level and high risk stratification were associated with higher level of biochemical recurrence. These results are in accordance to literature (15-21).

Biochemical recurrence following RP was more frequent in patients with Gleason score 8-10, higher PSA level and those considered of high 
risk, also in accordance to literature (5,7,22-25).

Three different radiotherapy techniques were used throughout the study: RTCo, RT2D and RT3D. The three groups of patients were compared and there were a lower number of recurrences in patients submitted to RT3D. The use of RT3D allows the use of higher doses associated to better therapeutic results (26-28).

Biochemical recurrence was identified in only $15 \%$ of patients submitted to RT3D. The low number of recurrences in this group of patients probably did not allow the identification of a relationship between recurrence level and associated risk factors.

The lower level of recurrence in patients submitted to RT3D is not explained by different pre-treatment characteristics among patients. They were uniformly distributed among the three modalities of radiotherapy. However, it is important to observe that the time of follow-up was lower in those patients than those treated with cobalt or RD2T radiotherapy; eventually during a longer follow-up more recurrence episodes will be identified.

The comparison of RT and RP did not show any statistical difference regarding biochemical recurrence. Available data in literature cannot conclude that one treatment is better than the other in any risk group of disease (3).

\section{CONCLUSIONS}

RT and RP have similar results. Today $\mathrm{RT}$ is more efficient than those previously used. Risk factors and treatment results are in accordance to literature data.

\section{CONFLICT OF INTEREST}

None declared.

\section{REFERENCES}

1. World Cancer Research Fund International. Cancer Statistics: Worldwide. Accessed February 27, 2013. Available at http://www.wcrf.org/cancer_statistics/world_ cancer_statistics.php.
2. Instituto nacional do câncer. Estimativa 2012: Incidência de Câncer no Brasil. Accessed February 27, 2013. Available at http://www.inca.gov.br/estimativa/2012/ estimativa20122111.pdf.

3. Thompson I, Thrasher JB, Aus G, Burnett AL, Canby-Hagino ED, Cookson MS,et al.: Guideline for the management of clinically localized prostate cancer: 2007 update. J Urol. 2007; 177: 2106-31.

4. National Comprehensive Cancer Network. Clinical practice guidelines in oncology - Prostate Cancer, version 2.2013. Available at nccn.org. Accessed in May 23, 2013.

5. Freedland SJ, Humphreys EB, Mangold LA, Eisenberger M, Dorey FJ, Walsh PC,et al.: Risk of prostate cancer-specific mortality following biochemical recurrence after radical prostatectomy. JAMA. 2005; 294: 433-9.

6. Agarwal PK, Sadetsky N, Konety BR, Resnick MI, Carroll PR; Cancer of the Prostate Strategic Urological Research Endeavor (CaPSURE): Treatment failure after primary and salvage therapy for prostate cancer: likelihood, patterns of care, and outcomes. Cancer. 2008; 112: 307-14.

7. Ward JF, Blute ML, Slezak J, Bergstralh EJ, Zincke H: The long-term clinical impact of biochemical recurrence of prostate cancer 5 or more years after radical prostatectomy. J Urol. 2003; 170: 1872-6.

8. Amling CL, Bergstralh EJ, Blute ML, Slezak JM, Zincke H: Defining prostate specific antigen progression after radical prostatectomy: what is the most appropriate cut point? J Urol. 2001; 165: 1146-51.

9. Gretzer MB, Trock BJ, Han M, Walsh PC: A critical analysis of the interpretation of biochemical failure in surgically treated patients using the American Society for Therapeutic Radiation and Oncology criteria. J Urol. 2002; 168: 1419-22. Erratum in: J Urol. 2002; 168: 2558.

10. Kuban DA, Thames HD, Shipley WU: Defining recurrence after radiation for prostate cancer. J Urol. 2005; 173: 1871-8.

11. Boccon-Gibod L, Djavan WB, Hammerer P, Hoeltl W, Kattan MW, Prayer-Galetti T, et al.: Management of prostate-specific antigen relapse in prostate cancer: a European Consensus. Int J Clin Pract. 2004; 58: 382-90. Erratum in: Int J Clin Pract. 2004; 58: 648.

12. Moul JW: Prostate specific antigen only progression of prostate cancer. J Urol. 2000; 163: 1632-42.

13. [No authors listed]: Consensus statement: guidelines for PSA following radiation therapy. American Society for Therapeutic Radiology and Oncology Consensus Panel. Int J Radiat Oncol Biol Phys. 1997; 37: 1035-41.

14. Roach M 3rd, Hanks G, Thames H Jr, Schellhammer P, Shipley WU, Sokol GH, et al.: Defining biochemical failure following radiotherapy with or without hormonal therapy in men with clinically localized prostate cancer: recommendations of the RTOG-ASTRO Phoenix Consensus Conference. Int J Radiat Oncol Biol Phys. 2006; 65: 965-74. 
15. Partin AW, Kattan MW, Subong EN, Walsh PC, Wojno KJ Oesterling JE, et al.: Combination of prostate-specific antigen, clinical stage, and Gleason score to predict pathological stage of localized prostate cancer. A multiinstitutional update. JAMA. 1997; 277: 1445-51. Erratum in: JAMA 1997; 278: 118.

16. P. Kupelian, J. Katcher, H. Levin, C. Zippe, and E. Klein: "Correlation of clinical and pathologic factors with rising prostate-specific antigen profiles after radical prostatectomy alone for clinically localized prostate cancer" Urology, 1996; 48: 249-60.

17. Lowe BA, Lieberman SF: Disease recurrence and progression in untreated pathologic stage T3 prostate cancer: selecting the patient for adjuvant therapy. J Urol. 1997; 158: 1452-6.

18. Green GA, Hanlon AL, Al-Saleem T, Hanks GE: A Gleason score of 7 predicts a worse outcome for prostate carcinoma patients treated with radiotherapy. Cancer. 1998; 83: 971-6.

19. Epstein JI, Pound CR, Partin AW, Walsh PC: Disease progression following radical prostatectomy in men with Gleason score 7 tumor. J Urol. 1998; 160: 97-100; discussion 101.

20. Albertsen PC, Fryback DG, Storer BE, Kolon TF, Fine J: Long-term survival among men with conservatively treated localized prostate cancer. JAMA. 1995; 274: 626-31.

21. Albertsen PC: A challenge to contemporary management of prostate cancer. Nat Clin Pract Urol. 2009; 6: 12-3.

22. Pound CR, Partin AW, Eisenberger MA, Chan DW, Pearson JD, Walsh PC: Natural history of progression after PSA elevation following radical prostatectomy. JAMA. 1999; 281: $1591-7$.

23. Zhou P, Chen MH, McLeod D, Carroll PR, Moul JW, D'Amico AV: Predictors of prostate cancer-specific mortality after radical prostatectomy or radiation therapy. J Clin Oncol. 2005; 23: 6992-8.
24. D'Amico AV, Moul JW, Carroll PR, Sun L, Lubeck D, Chen $\mathrm{MH}$ : Surrogate end point for prostate cancer-specific mortality after radical prostatectomy or radiation therapy. J Natl Cancer Inst. 2003; 95: 1376-83.

25. Freedland SJ, Humphreys EB, Mangold LA, Eisenberger M, Dorey FJ, Walsh PC,et al.: Death in patients with recurrent prostate cancer after radical prostatectomy: prostate-specific antigen doubling time subgroups and their associated contributions to all-cause mortality. J Clin Oncol. 2007; 25: 1765-71.

26. Pollack A, Zagars GK, Starkschall G, Antolak JA, Lee JJ, Huang E, al.: Prostate cancer radiation dose response: results of the M. D. Anderson phase III randomized trial. Int J Radiat Oncol Biol Phys. 2002; 53: 1097-105.

27. Zietman AL,. DeSilvio M L, Slater J D, et al.: "Comparison of conventional-dose vs high-dose conformal radiation ther-apy in clinically localized adenocarcinoma of the prostate: a randomized controlled trial". JAMA. 2005; 294: 1233-9.

28. Peeters ST, Heemsbergen WD, Koper PC, van Putten WL, Slot A, Dielwart MF, et al.: Dose-response in radiotherapy for localized prostate cancer: results of the Dutch multicenter randomized phase III trial comparing 68 Gy of radiotherapy with 78 Gy. J Clin Oncol. 2006; 24: 1990-6.

Correspondence address: Danielle A. Zanatta, MD Assis Gurgacz (FAG) Medical School Avenida das Torres, 500 - Loteamento Fag Cascavel, PR, 85806-095, Brazil

Telephone: + 5545 3321-3900 Email: daniellezanatta@gmail.com 